\title{
A lenda do Curucutu e outras histórias: um estudo sobre a utilização de histórias infantis como mecanismos de disciplinamento
}

\section{The legend of Curucutu and other stories: a study on the use of children's stories as discipline mechanisms}

\author{
Sharlene Wenz Havenstein ${ }^{1}$
}

\begin{abstract}
Resumo
É muito comum, na educação infantil e nas séries iniciais, a prática pedagógica de contar histórias infantis. Partindo-se do pressuposto, amplamente difundido pela literatura especializada, segundo o qual a escola é um espaço de disciplinamento, observa-se a utilização de histórias infantis como recurso prático para acionar, por parte dos professores, recursos que colimam na constituição de mecanismos disciplinares no meio escolar, quer por meio explícito, quer de modo eufemizado e, que talvez, os professores não se deem conta dos mesmos. Em razão disso, o objetivo aqui é desvelar como são mobilizados os mecanismos disciplinares nas histórias infantis contadas em classes de alfabetização.

Palavras-Chave: Histórias infantis. Disciplinamento. Práticas pedagógicas.
\end{abstract}

\begin{abstract}
The pedagogical practice of telling stories is very common in early childhood education and in the early grades. Based on the assumption widespread by the literature according to which the school is a space for discipline, it is observed that children's stories are used as a practical resource triggered by teachers aiming at the constitution of disciplinary mechanisms in the school environment, either through explicit or euphemized way, but it is possible that the teachers are unaware of them. Thus, our purpose is to reveal how disciplinary mechanisms are mobilized in the children's stories told in literacy classes.

Keywords: Children's Stories. Discipline. Pedagogical Practices.
\end{abstract}

\section{Introdução}

Durante a vida, um sujeito passa por várias instituições: a escola, a fábrica, o hospital e, por vezes, a prisão. A escola, como instituição disciplinadora, apresenta sinais de uma “[...] grande atenção dedicada ao corpo, que se manipula, modela-se, treina-se, que obedece, que responde, se torna hábil ou cujas forças se multiplicam" (FOUCAULT, 2007, p. 117).

Este processo de institucionalização decorre da necessidade de normalizar e de conformar os indivíduos tornando as instituições, seja qual for, mais produtivas. Diante disso, a disciplina temse se constituído como uma das maneiras mais eficazes para dar conta da organização e sujeição dos indivíduos. Essas instituições se configuram e organizam de modo a formar no corpo do indivíduo características de produtividade e adaptação. Os mecanismos presentes nessas instituições deixam nos sujeitos as características desejáveis à vida em sociedade. A escola ainda é considerada por muitas famílias e alunos e alunas um lugar de crença e esperança de um futuro melhor para quem passar por ela e, portanto, é valorizada pela comunidade. Desse modo, não se pode deixar de mencionar que

\footnotetext{
${ }^{1}$ Mestranda em Educação pela Universidade Regional de Blumenau. Pedagoga, especialista em educação infantil, alfabetização, supervisão, orientação educacional e gestão escolar. Coordenadora Pedagógica na Escola de Educação Básica Luiz Delfino. Email: sharlenewenz@gmail.com
} 
seus efeitos ficam marcados nos sujeitos, que muitas vezes se orgulham de ter tais comportamentos por terem apreendido-os na escola. Sendo assim, tornase essencial mencionar os mecanismos disciplinares presentes na escola, pois ela é uma das instituições responsáveis pela domesticação dos sujeitos.

As instituições controlam a conduta humana a partir de certos padrões previamente definidos. A instituição é inseparável do caráter controlador e disciplinador. Segundo Foucault (2007), a disciplina é necessária para o funcionamento das instituições e para o disciplinamento da sociedade. Para tanto, faz-se uso do poder disciplinar, ou seja, um método que permite o controle minucioso sobre o corpo, sujeitando-o e impondo a ele uma relação de docilidade-utilidade. O poder disciplinar fabrica diferenças que agrupam e separam de acordo com suas individualidades, e ainda segundo Foucault, o corpo é alvo de poder e, portanto, é exercida sobre ele uma coerção sem folga. E é por meio deste domínio sobre o corpo dos indivíduos que a disciplina fabrica corpos dóceis, úteis, submissos e normalizados. Para isso, ela controla o tempo e as atividades, avalia, classifica ou desclassifica, faz regras, uniformiza, certifica, "forma" os sujeitos, ou seja, os mecanismos disciplinares são uma forma de produzir nos sujeitos as condutas que dele são esperadas.

É por isso que estes mecanismos estão presentes desde a escola, auxiliando na formação do futuro cidadão, passivo e disciplinado, pois o exercício do poder incita, induz e desvia os comportamentos do indivíduo em disciplinamento.

A disciplina em todas as instituições, entenda-se aqui, escolas, prisões, hospitais e fábricas, exerce as seguintes funções descritas por Foucault (2007, p. 143),

A disciplina 'fabrica' indivíduos; ela é a técnica específica de um poder que toma os indivíduos ao mesmo tempo como objetos e como instrumentos de seu exercício. Não é um poder triunfante que, a partir de seu próprio excesso, pode-se fiar em seu superpoderio; é um poder modesto, desconfiado, que funciona a modo de uma economia calculada, mas permanente.

Em síntese, a combinação calculada destas estratégias é a forma mais eficaz da prática disciplinar e esse é o papel a função da escola moderna. Cabe aqui lembrar que as estratégias usadas para o disciplinamento passam a ser uma violência produzida e sentida na escola. Uma violência simbólica, como dizia Pierre Bourdieu, pois são condições sociais reproduzidas pela inculcação e imposição de autoridades que possuem mais força e poder do que os sujeitos que sofrem a inculcação e o disciplinamento.

Estar na escola, viver na escola é, muitas vezes, uma situação angustiante. Por um lado sabemos e desejamos fazer diferente, modificar algumas coisas e, até mesmo, tentamos, de forma bem ingênua, resolver. Por outro lado, o cotidiano vai sendo tomado por frustrações, desânimos, inúmeros questionamentos e, por vezes, sentimos que as regras da sociedade disciplinar ainda não foram abandonadas, mesmo que se fale em pedagogias lúdicas e novas concepções de educação e ensinoaprendizagem. Continua-se vigiando, punindo, e surgem novas formas de utilização das técnicas de disciplinamento e reprodução, como meio para garantir a continuidade histórica do processo de docilização.

Segundo Tomelin (2005), há novas técnicas nas atividades escolares, eufemizadas ou não e elas muitas vezes são dotadas de qualidades como ritmo e harmonia, mas muitas outras são um momento de criação da ordem. Entre elas podem ser citadas a ordem. Técnicas aparentemente lúdicas, como histórias ou jogos infantis introduzem na vida uma perfeição temporária e limitada, produzem isolamento e limitação. Estas atividades possuem um lugar, limites de espaço e tempo.

É possível identificar técnicas de disciplinamento que se revestem com um caráter lúdico, divertido e modernizado. Identifica-se essa prática em momentos como a contação de histórias infantis 
para as crianças, a exemplo da lenda do Curucutu, cuja autora é uma professora de séries iniciais da rede estadual de Santa Catarina.

Havia na floresta um velho muito enrugado, feio e esquisito. O nome dele era Curucutu [...]. Ele está a procura de um filho que tem cerca de seis ou sete anos [...]. A professora é amiga do Curucutu e vai devolver o filho para o Curucutu se ela encontrá-lo [...]. O Curucutu não toma banho, só come minhocas, batatas, aranhas e cobras e não pára quieto [...].

Percebe-se neste momento, o êxtase, o ar amedrontado, assustado, estampado nos semblantes das crianças, motivado pelo "terror" velado pelo som da história ouvida.

\section{Histórias Causadoras de Temor}

Existem histórias infantis que levam o leitor e o ouvinte para uma viagem no mundo da fantasia, do sonho e da alegria. São histórias contadas e recontadas ao longo dos tempos. Ao mesmo tempo, existem histórias que são capazes de levar a criança para o mundo do terror, do medo e angústia.

$\mathrm{O}$ acúmulo de agressões que atingiram as populações entre os séculos XVII e XIX, fez surgir o que Delumeau (1989, p. 32) chamou de país do medo no qual "uma civilização se sentiu 'pouco à vontade' e povoou de fantasmas mórbidos". A angústia se arrastava pela sociedade, se espalhava e submetia o indivíduo a estresses repetidos. Foi uma fase de criação de histórias que multiplicaram fobias, negatividade e desespero. O medo inculcado nos sujeitos modelou os corpos.

Certas personagens têm o poder de inibir comportamentos. Leiam-se aqui os contos de Hans Christian Andersen nas figuras de lobo mau na história da Chapeuzinho Vermelho ou, então as histórias de Walt Disney, a bruxa com sua maçã envenenada capaz de eliminar quem quer que esteja no caminho e que seja um estorvo para atingir os seus objetivos.... em Branca de Neve e os Sete Anões.
As histórias se utilizam-se de movimentos disciplinadores e eles são frequentemente colocados à tona. As crianças não pensam, nem demoram para entender o que se espera delas, conseguir ordem e obediência.

A preocupação desta prática pedagógica se faz presente na ação da qual resulte o nivelamento da cultura, moral e postura. A explicação disso está em muitas vezes se encontrar em livros infantis, informações acerca da cultura de um povo e elas em nenhum outro lugar foram registradas.

Em histórias como a Lenda do Curucutu, há a interação das crianças para que se torne nitidamente real o que se passa, pois possibilita inclusive, a oportunidade de as mesmas testemunharem os momentos de escrita de cartas endereçadas para a personagem Curucutu. Neste momento, observa-se o silêncio que se faz presente e sente-se a apreensão no olhar das crianças, que creem que tudo é verdadeiro e realmente vai acontecer.

Sendo assim, se alguém encontrar por aí, uma criança que se mexe igual a uma minhoca, se sacoleje inteira e não pára quieta, pode ter certeza, é o filho do Curucutu. É só entrar em contato com a professora, que ela mesma se encarrega de devolver o filho do Curucutu para o pai, que mora lá na floresta e espera ansioso para ensinar seu filho a ser um verdadeiro Curucutu.

Não basta docilizar o corpo, tornar as crianças quietas pelo medo de serem levadas para outras “dimensões" que não sejam as palpáveis por elas, ainda é pouco para obter o que se espera de um aluno em sala de aula. Sabe-se que as crianças tentam pelo menos se comunicar de outras formas, buscam outros artifícios. Em pouco tempo, descobrem que podem se comunicar por meio de disfarçados cochichos, por exemplo. Assim, se conseguem um espaço, os cochichos começam a circular o ambiente da sala de aula, e quando veem, já acalmaram a sensação amedrontadora que há poucos instantes vivenciavam. 
Evidentemente a comunicação não é a atitude esperada nos alunos. Eles não deveriam falar, nem perturbar as aulas com o barulho de suas vozes. Caso isso ocorra, a conclusão é muito simples; não há disciplina. Quando se espera a disciplina dos alunos, se está levando em consideração a seguinte concepção:

[...] O momento histórico das disciplinas é o momento em que nasce uma arte do corpo humano, que visa não unicamente o aumento de suas habilidades, nem tampouco aprofundar sua sujeição, mas a formação de uma relação que no mesmo mecanismo o torna tanto mais obediente quanto é mais útil, e inversamente. Forma-se então uma política das coerções que são um trabalho sobre o corpo, uma manipulação calculada de seus elementos, de seus gestos, de seus comportamentos. O corpo humano entra numa maquinaria de poder [...] (FOUCAULT, 2007, p. 119).

Assim que se percebe que o efeito esperado em disciplinamento não acontece, ou seja, os alunos apresentam, ainda, comportamento indisciplinar, outras histórias, com tons mais aterrorizantes, imaginando ser a melhor atitude a ser tomada neste momento, tomam o ambiente para que voltem ao silêncio, como por exemplo, a lenda do Beuzebu.

Nesta história, o Beuzebu tinha um plano de fundo semelhante ao Curucutu.

Ele também tinha perdido um filho pequeno e, atualmente, tinha a mesma idade de alunos da classe de alfabetização. Comia coisas nojentas e falava muito porque era um papagaio que tinha um filho humano. Então, seu filho, assim que fosse encontrado seria devolvido para o pai. E a característica para identificá-lo? Fala demais!

Quando os alunos ouvem isto, sentem-se novamente aflitos e confirmam por meio de mais uma história, de que "realmente é verdade, existe sim a possibilidade de serem levados para as personagens principais das histórias contadas".

Agora o trabalho de reprodução dos comportamentos desejados pela escola e sociedade já parece mais completo. Os alunos já estão com o corpo disciplinado, pois o Curucutu os engessou e as bocas estão fechadas porque o Beuzebu as calou. Por enquanto, a sensação que se tem é de que existe a possibilidade de se trabalhar em sala de aula com mais atenção e alívio. O contentamento que paira no ambiente está ligado ao sabor de vitória, de missão cumprida. O que se lê é que os alunos finalmente estão disciplinados e sob controle.

A disciplina fabrica assim corpos submissos e exercitados, corpos "dóceis". A disciplina aumenta as forças do corpo (em termos econômicos de utilidade) e diminui essas mesmas forças (em termos políticos de obediência). [...] digamos que a coerção disciplinar estabelece no corpo o elo coercitivo entre uma aptidão aumentada e uma dominação acentuada (FOUCAULT, 2007, p. 119).

Estas personagens aterrorizadoras parecem mágicas. O silêncio toma conta da sala. Estas lendas têm o poder de controlar o comportamento por horas de aula, sem que se precise lembrar os alunos sobre a existência de regras, silêncios ou medos.

Histórias contadas, sobretudo, "para divertir e entreter a criança pequena, são dirigidas para o desenvolvimento moral da infância, expresso no controle de impulsos considerados inadequados [...], na correção de más ações [...] ou maus costumes [...], na previsão dos perigos manifestos ao não se seguir os conselhos familiares" e escolares (ANDRADE; BONA; PEREIRA, 2005, p. 5).

As condições imediatas de criação das obras mencionadas se justificam desde que os alunos gostam de histórias. Então se une o útil ao agradável. A função delas é só manter a ordem, para que eles sejam bons alunos. Benjamin escreve sobre os objetivos das histórias infantis no século XIX. "Se o homem era piedoso, bom e sociável por natureza, então poderia ser possível fazer da criança, ser natural por excelência, o homem mais piedoso, mais bondoso e mais sociável" (BENJAMIN, 1984, p. 49). Não há nada mais normal do que tomar 
medidas que tornem as crianças boas e sociáveis, dóceis e agradáveis, legítimos reprodutores de um valor social, civilizados e absolutamente bem disciplinados.

Aliás, o mais curioso desta situação é que as histórias infantis, neste contexto, estão sendo criadas e utilizadas no século XXI, ou seja, hoje, com os mesmos objetivos que se tinha no século XIX, quando foram escritas histórias como as de Struwwelpeter, história infantil escrita no século XIX.

Esses personagens "eram como papões ou terríveis figuras do outro mundo, [...] para devorar ou arrebatar meninos maus. [...] Esta macabra, terminando na morte de uma criança, escolhida entre as de pior comportamento [...] O fim, o moral, o pedagógico, de influir pelo medo ou pelo exemplo do castigo.” (FREYRE, 2004, p. 199).

Curucutu, Beuzebu e Zebedeu. Estes nomes fazem parte de acervos inúmeros de personagens das histórias infantis com finalidades disciplinadoras.

\section{Outras Histórias... Mais Disciplina}

A lenda do Curucutu fez lembrar um livro infantil alemão, escrito por um médico chamado Heinrich Hoffmann, cujo título é Der Struwwelpeter, em português, o menino desleixado. A lenda do Curucutu, assim como Der Struwwelpeter, são dotados de um conjunto de atributos simbólicos, constituem uma técnica de educação que hoje já não é mais tão comumente utilizada para ensinar valores e moral para as crianças, de modo que a história conta com dureza e fatalidade, e uma espécie de terrorismo ao longo de todo o seu texto.

O livro Struwwelpeter, estudado e analisado por Andrade; Bona e Pereira (2005) diz respeito aos propósitos de educação dos impulsos e dos costumes. Sua história “objetiva o fortalecimento do autocontrole, a inibição de paixões e o controle de pulsões, tornar as condições externas em autorestrições ou auto-regulações para si mesmos."
Ou seja, a história objetiva inculcar na criança o controle dos impulsos de conduta e emocionais e desenvolver o espírito de previsão, ou seja, se eu não ficar quieto, vou ser levado para viver com o Curucutu.

A utilização dessas histórias, conforme Benjamin (1984, p. 48-49) conduz à prática de formação do sujeito dócil, bondoso e sociável. A dedicação ao trabalho moral é tão grande que a dedicação é quase que exclusiva para a criação de histórias drásticas e áridas, e geralmente sem significado para as crianças.

Para obter-se um bom comportamento das crianças, há outros livros de literatura para crianças, como por exemplo, Se ligue em Você. Este livro, de publicação contemporânea, ensina que crianças que fazem coisas boas, tem bons comportamentos, obedecem pais e professores, e não insistem em pedir algo que não ganham, são crianças boas e têm uma luz acesa em seu peito. Já as crianças birrentas, desobedientes, choronas e que reclamam de tudo, têm a sua luz apagada e que, portanto, ninguém gosta delas. A história é escrita de um modo muito engraçado e simples, e não há criança que não guarde estas informações na memória e que não controle seu próprio comportamento bem como o dos colegas para garantir que as "luzes não se apaguem" de seus corações. É perceptível este fato quando se fala para a turma depois da leitura do livro, "Todos sentados e quietos. Não quero ouvir nenhum piu, caso contrário a luz dos corações de vocês serão apagadas!'Esta situação de temor acontece sempre quando se mencionam em sala de aula, trechos do livro, depois do livro anteriormente mencionado ter sido lido para as crianças.

O livro "Se ligue em você", está sendo usado nestes momentos para a manutenção da ordem, para a reprodução do processo civilizatório. Percebese que nesta ação, "A civilização não é apenas um estado, mas um processo que deve prosseguir". (ELIAS, 1990, p. 62), e que se realiza as ações adequadas para que este processo se concretize. É 
um modo de reproduzir "um tipo mais elevado de sociedade: a idéia de um padrão moral e costumes, isto é, tato social, consideração pelo próximo, e numerosos complexos semelhantes." (ELIAS, 1990, p. 62).

Observa-se que o processo pedagógico realizado nas instituições escolares, faz o que Bourdieu chama de Trabalho Pedagógico, "[...] trabalho de inculcação que deve durar o bastante para produzir uma formação durável; isto é, um habitus como interiorização dos princípios de um arbitrário cultural capaz de perpetuar-se após a cessação da Ação Pedagógica e por isso de perpetuar nas práticas os princípios do arbitrário interiorizado." (BOURDIEU; PASSERON, 2007, p. 53).

O sociólogo francês Pierre Bourdieu, em sua obra $A$ reprodução e o filósofo francês Michel Foucault em "Vigiar e Punir", relatam os fundamentos para a prática pedagógica, no caso do contexto mencionado, as histórias infantis, como mecanismo de disciplinamento e reprodução das produções sociais estabelecidas como adequadas e rentáveis. Desse modo, o Curucutu e as demais histórias estão sendo usadas pelos (as) professores (as) alfabetizadores (as) como mecanismo de reprodução da disciplina validada pela sociedade disciplinada.

\section{Considerações Finais}

A instituição escolar, ao longo da história, tem feito uso de vários aparatos pedagógicos, disciplinares e arquitetônicos para constituir nos indivíduos, desde o primeiro momento de sua entrada nesta instituição, características homogêneas que possibilitam à escola um controle eficiente e produtivo sobre aqueles que por ela são "educados e ensinados".

"O mundo social exige a existência de um determinado tipo de homem para satisfazer os seus interesses. Por meio da educação, ela renova perpetuamente as condições tornando possível a sua sobrevivência." (TOMELIN, 2005, p. 5). Nesse sentido, é possível perceber que o trabalho pedagógico em classes de alfabetização se faz no sentido de perpetuar e manter os "bons" costumes por meio das histórias infantis.

As técnicas de leituras de livros infantis são utilizadas para disciplinar e produzir individualidades organizadas e tranquilas para a instituição. Assim também, outras técnicas como a fila, o controle do horário, a divisão de conteúdos séries e a combinação de forças são atividades diárias nas instituições escolares.

Foucault (2007) afirma existir uma relação de fiscalização inserida na prática de ensino. A manutenção de um olhar permanente, que tem como objetivo anotar, observar, registrar e classificar produz nos sujeitos a certeza de sempre poder estar sendo vigiado. Deste modo, a instituição escolar se torna um local de vigilância e observação constantes.

Fica evidente que, em situações de sala de aula, o uso da literatura infantil como instrumento que assusta e constrange, ainda é uma prática constante. Dessa forma, revela que as escolas têm práticas disciplinadoras planejadas e eufemizadas, transfigurando jogos e brincadeiras em instrumentos de controle, além da utilização da literatura infantil numa pedagogia voltada a instilar nas crianças o medo e, com isso, obter delas comportamentos desejados e tidos como legítimos no espaço escolar.

O disciplinamento nas instituições escolares surpreende pela sua capacidade de se disfarçar sem perder de vista seus interesses primeiros, ou seja, a produção de indivíduos socialmente adaptados, disciplinados. Esta capacidade de disfarçar os objetivos de suas atividades produz a crença ilusória da criação de novas metodologias pedagógicas, porém metodologias que ficam presas em suas antigas concepções. São práticas e métodos antigos, de décadas e séculos passados presentes nas escolas de hoje como características de uma pedagogia contemporânea e moderna. 
Desde as histórias aterrorizantes até as brincadeiras do recreio que é vigiado e resulta em punição dos que fogem às regras, a escola consegue o controle sobre o corpo do outro. Além disso, as histórias trazem regras e conforme Château (1987), crianças não vivem sem regras, porque nelas encontram o instrumento seguro de sua afirmação, permanência e autonomia. Para Château, sem regras, as crianças permanecem instáveis e com dificuldades na relação social.

A utilização de histórias infantis torna-se uma maneira de evitar comportamentos indesejados e formar sujeitos bem disciplinados, por meio de técnicas sutis e lúdicas.

Neste sentido, utilizar histórias infantis e "educativas", são práticas aceitas sem nenhuma resistência, uma vez que aproveitar o tempo e educar, é "muito melhor deixá-los assim do que sem ter o que fazer", conforme a fala de alguns educadores que se escuta pelos corredores das instituições escolares, reproduzindo e incorporando assim, seu próprio discurso pelo reforço e convencimento.

Restam ainda possibilidades para se pensar nas diversas roupagens adotadas pelo poder disciplinar e na transfiguração de suas técnicas. Ou seja, pensar quantas e quais práticas pedagógicas escondem em seu interior os resquícios da disciplina. Outra possibilidade é pensar na importância do brincar espontâneo e do trabalho com a literatura sem a utilização do terror e sem intenções disciplinadoras em seu conteúdo.

\section{Referências}

ANDRADE, Maria da Conceição Lima de; BONA, Melita; PEREIRA, Gilson Ricardo de Medeiros. Controle das pulsões e coerção pela previdência em histórias infantis. In: CONGRESSO INTERNACIONAL DE EDUCAÇÃO, 4., 2005, São Leopoldo. Anais... São Leopoldo, 2005. v. 1, p. 1-12.

BENJAMIN, Walter. Reflexões: a criança, o brinquedo, a educação. São Paulo: Summus, 1984.

BOURDIEU, Pierre; PASSERON, Jean Caude. A reprodução: elementos para uma teoria do sistema de ensino. Petrópolis, RJ: Vozes, 2007.

CHÂTEAU, Jean. O jogo e a criança. São Paulo: Summus, 1987.

DELUMEAU, Jean. História do medo no ocidente: 1300-1800, uma cidade sitiada. São Paulo: Companhia das Letras, 1989.

ELIAS, Norbert. O processo civilizador: uma história dos costumes. Rio de Janeiro: Jorge Zahar, 1990.

FOUCAULT, Michel. Vigiar e punir: história das violências nas prisões. 34. ed. Petrópolis, RJ: Vozes, 2007.

FREYRE, Gilberto. Casa-grande \& senzala: formação da família brasileira sob o regime da economia patriarcal. São Paulo: Global, 2004.

TOMELIN, Karina Nones. O recreio é legal: um estudo sobre os mecanismos disciplinares e sua eufemização em atividades escolares. 2005. 92 f. Dissertação (Mestrado em Educação) - Universidade Regional de Blumenau, Blumenau.

Recebido em: maio 2010

Aceito em: julho 2010 
